wool in 1900. 'This will be possible because of the imaginative rescarch and development work largely carried out in the laboratories of the principal fibre producers. Chemists and physicists in other institutions have also provided fundamental theories which have been valuable in the development of new fibres or in the improvement of well established ones. The literature on man-made fibres is therefore scattered and much of it has only a limited circulation. Patent specifications are a valuable, if confusing, source of information.

There are not many up to date good textbooks on the science and technology of man-made fibres and therefore the present volume, which is the first of a series of three, is to be welcomed. It is edited by three distinguished scientists and each chapter is written by an expert in the field.

Professor Mark and Dr Atlas open the work with an excellent essay on the structural principles of fibre-forming polymers and this is followed by chapters on fibrespinning processes, wet-spinning solutions, solution dryspinning, melt-spinning, and spinning of emulsions and suspensions. The remaining chapters are concerned with transition phenomena and their importance in fibre structure, the role of chain folding in determining fibre characteristies and current ideas on the morphology of synthetic fibres. The book is completed by an article on conjugate or bicomponent fibres by members of the Du Pont Benger Laboratory.

The treatment of each topic is of a uniformly high level. The emphasis is on the physical and mathematical aspects, but at the same time much valuable and interesting technical information is included.

The book is well written; it is a mine of scientific information and will be invaluable to all concerned with modern fibre science. It is also a striking exposition of how much the modern man-made fibres industry owes to scientists and engineers and of the sophisticated and challenging nature of the research associated with the commercial production of man-made fibres.

C. S. WHEWELL

\section{CRAZES AND CRACKS}

Fracture in Polymers

By E. H. Andrews. (Oliver and Boyd: Edinburgh and London, 1968.) $63 s$.

For the effective application of any material a knowledge of the conditions under which failure occurs is essential. The metallu.gist has long recognized that in metals there is a close correlation between the deformation and fracture characteristics and the internal structure and, in particular, that minute changes in physical and/or chemical constitution may produce pronounced changes in property which if not recognized and accounted for could be catastrophic in service. The correlation between structure and property is becoming increasingly emphasized in polymers and this book demonstrates some of the features of this correlation in an interpretation and understanding of fracture. As this typo of approach to polymers is relatively new it is not surprising that much of tho book is at an elementary level in comparison with similar texts on metals.

The general approach is from first principles and in the first chapter there is a simple account of the structure of polymers and an introduction to the factors which determine the response of polymers to an applied stress. The next two chapters provide a phenomenological account of the macroscopic features of fracture and the effect of variables such as temperature, strain rate, stress system, polymer constitution and structure, and environ. ment on the fracture behaviour. In chapters 4 and 5 the basic ideas of crack nucleation and propagation are described and finally in chapter 6 some rather random observations on the appearance of the fracture surfaces of polymers are described.

Throughout the book the author looks over his shoulder at the techniques and physical interpretations which have been used to understand the fracture of metals and this is reflected also in the overall approach. Unfortunately, there are one or two topics in which the approach is clearly metallurgical but the understanding is somewhat different from the one used by the metallurgist. I refer particularly to the concepts associated with crack initiation and its relation to propagation. The idea of crack initiation in metals implies that some micromechanistic process (local plastic deformation) generates sufficient local stress to produce a microcrack. This may or may not propagate depending on the macroscupic stress field. The author implies that initiation in plasties involves the start (initiation) of propagation of a preexisting flaw in line with the basic proposition of Griffith. I think this leads to a misunderstanding of the general phenomena of fracture in polymers, because pro-existing flaws are unlikely to be a common feature of polymers, and cracks must be initiated by similar processes to those in metals.

The book surveys most of the work which has been directed towards an understanding of the basic fracture behaviour, and at the end of each chapter there is a useful list of references. There is very little reference to work in the last two or three years and one suspects that there was a long publication gap. If reference had been made to recent work the confusion about crazes and cracks would have been avoided.

As an introduction to the subject this book will be useful for undergraduate teaching and for research workers who are developing an interest in this field. The text is well illustrated by line drawings and, as Sir Harry Melville comments in the foreword, the author has produced a most readable and logical approach to the subject. I welcome the book, particularly, because it places on record the important concept of the connexion between structure and property.

D. HULt

\title{
TESTING AT SPEED
}

\section{High Speed Testing}

Vol. 6: The Rheology of Solids. (Sixth International Symposium held at Boston, Mass., March 6 and 7, 1967. Applied Polymer Symposia, No. 5.) Pp. viii + 344. (Interscience (Wiley): New York and London, 1967.) $117 s$.

The Rheology of Solids is the sixth volume in a series of biannual symposia on high speed testing, volumes 5 and 6 having been incorporated as Nos. 1 and 5 of the Applied Polymer Symposia series associated with the Journal of Applied Polymer Science. The subject matter is that of the behaviour of materials under non-quasistatio loading conditions, a topic which docs not receive the attention it merits except in those industries, such as aerospace, where it cannot be avoided by static over design. The futility of this approach might be illustrated by a specific example from the symposium in which it is shown that although nylon tyre cord is superior to polyestor at low loading rates, the reverse is true in more realistic high speed testing.

The majority of the papers in the current volume are directly concerned with the effect of strain, strain rate and temperature on the resistance to deformation and failure of polymers (including textiles and foams) and metals. Both impulsive and steady strain rate tests are described and the results show the characteristic tendency for increas. ing material resistance at higher strain rates and lower temperatures.

Two papers deal with rheo-optical effects using photographic and intensity techniques, one containing a description of a testing machine designed to strain both 